\title{
Elementary Teachers' Perspectives on the Use of Multicultural Literature in Their Classrooms
}

\author{
KAREN F. HOLLAND \\ Reading Specialist, Florida, US \\ GERALDINE MONGILLO \\ William Paterson University of New Jersey
}

\begin{abstract}
This qualitative study set out to determine how multicultural literature was used and perceived by US elementary school teachers, and how the beliefs of teachers shape perceptions, selection, interpretation, and the teaching of multicultural literature (Ketter \& Lewis, 2001).Twenty-six (26) elementary school teachers across the country responded to this study. An invitational email with a web-survey hyperlink was utilized. Variables pertaining to participant background, definition, selection acquirement and application of "multicultural" literature, the elementary school community and district mandates were addressed in the web survey. Findings revealed that all participants used multicultural literature sometime during the school year. The majority of participants were Caucasian females teaching in suburban schools, which did not have a mandated multicultural curriculum. Regardless of mandates, the majority applied a "narrow" definition for multicultural literature using the words "cultural", "race," and "nationality." Other findings indicated that elementary school teachers used multicultural literature more frequently when they had strong administrative support, regardless of their students' or their own ethnicity.
\end{abstract}

\author{
Keywords \\ elementary teachers, multicultural literature
}

\section{Introduction}

"Do you know who Dr. Ralph Bunche was?" I (Holland) had been looking for my childhood friend for 45 years, and found her because I knew the answer to this question. In the early '60's, when I was living in New York City, I had a friend named Karen Pierce. I later moved but thought of her often throughout the years. A few years ago, I asked my mother what she remembered about Karen and one of the things she told me was that Karen's grandfather was Ralph Bunche! ' I recalled hearing the name, and seeing it on a poster in Mrs. Chatham's (pseudonym) third-grade classroom where I student taught. After some research, I found Karen, and we eventually were reunited. I wanted to tell the story, but when I presented this question to educators and friends (who were of diverse backgrounds: African-Americans, Whites, Hispanics, Asians, etc.), few knew of him. As an aspiring reading teacher of European-American descent, I wondered about my peers' lack of background knowledge about the important contributions made by this great African-American leader. I became concerned about the possibility that the

1

${ }^{1}$ Dr. Ralph Johnson Bunche (August 7, 1903 - December 9, 1971) was an American political scientist and diplomat who received the 1950 Nobel Peace Prize for his late 1940s mediation in Palestine. He was the first person of color to be so honored in the history of the Prize. He was involved in the formation and administration of the United Nations. In 1963, he received the Medal of Freedom from President John F. Kennedy. Karen Pierce is Dr. Bunche's granddaughter. 
contributions of many leaders from diverse backgrounds were overlooked and/or omitted from the curriculum. I wanted to learn about the ways in which multiculturalism was defined and addressed in schools, which instigated the questions guiding this research study: "How are teachers addressing multicultural issues in their classrooms, and how do elementary teachers select multicultural literature to use in their classrooms?"

To begin, one must understand the meaning and intent of the term multicultural. It can be narrowly defined to mean ethnicity and race (culture). The term has also been more broadly defined to encompass issues of racism, sexism (gender), classism (socio-economic status), ableism (physical abilities), ageism (age), heterosexism (sexual orientation),

religious intolerance (values/morals), xenophobia (fear of strangers and different cultures), and linguicism (language/culture) (National Association for Multicultural Education, 2003).

With widespread immigration, nations struggle to maintain cultural identity while providing equity and acknowledgement for all its newcomers. Hence, concerns surrounding the definition of multiculturalism are debated on a global scale by both theorists and educators. As Lund (2006) observed:

Compounding this tumult are manifestations of nationalist perspectives that may employ similar terminology but in very different senses. Even among scholars who define themselves as working in the field of multicultural education there is a wide range of thought and activity that often confounds attempts to define a common purpose, or indeed, any meaningful expression of political solidarity among its avowed supporters toward social justice (p. 36).

Worldwide, educators have embraced the notion of a multicultural curriculum that would foster equity by teaching cultural awareness and tolerance. However, some eschew the term multicultural education because it has been seen as a failure to accomplish these goals because "it is often argued that multiculturalism places too much emphasis on difference and diversity" (Palaiologou \& Faas, 2012). Other educational systems have revised and/or renamed their educational programs (e.g., intercultural education; antiracist education; critical multicultural education) but what matters most is the content and purpose (Coulby, 2011), not what the program is called. The content should aim to promote inclusion of all cultures, social justice, and the celebration of diversity within the curriculum and beyond to include the entire school community.

In terms of education, The National Association for Multicultural Education (2016) set standards for multicultural education demanding:

[A] school staff that is culturally competent, and to the greatest extent possible racially, culturally, and linguistically diverse. Staff must be multi-culturally literate and capable of including and embracing families and communities to create an environment that is supportive of multiple perspectives, experiences, and democracy. (para. 5)

In US elementary schools, cultures other than the dominant "White" culture are recognized and discussed. Typically, multicultural literature is carefully selected and taught around the occurrence of specific ethnic holidays, recognizing one or two famous Americans of that specific ethnic group or race. In this way children may learn about minority leaders, and the various ethnic communities that make the country so diverse, but much of the literature choice 
varies from school to school. Teacher attitude toward the use of multicultural literature has a profound effect on students (Ladson-Billings, 2003). Although the role of the elementary school teacher in fostering respect and acceptance of other cultures is pivotal in this regard, the depth and quality of a teacher's multicultural education may vary.

\section{Theoretical Background}

Research has supported the importance of multicultural education (Jimenez, 2003; Nieto, 2006; Nieto \& Bode, 2012; Tschida, Ryan, \& Ticknor, 2014). Multicultural issues are being addressed in some classrooms, but it is primarily in elementary schools that multicultural literature is first used for children to learn about their racial and ethnic differences. Therefore, elementary teachers have the greatest opportunity to foster the development of positive, healthy attitudes towards others in their students.

\section{High Quality, Authentic Children's Multicultural Literature}

The importance of identifying both high quality and authentic multicultural literature is an important part of the selection process. The Cooperative Children's Book Center defines multicultural literature as books by and about people of color and First/Native Nations individuals: African and African Americans, American Indians, Asian/Pacific and Asian-Pacific Americans, and Latinos (n.d., Para. 1). However, it is not enough to include high quality literature from various cultures into the curriculum; teachers must also learn how to recognize authentic multicultural literature.

Determining authenticity is an issue that is fraught with controversy, however, researchers in the field (e.g., Bishop, 1990; Harada, 1995; Higgins, 2003; Lu, 1998) agree that the following criteria should be carefully evaluated to ascertain a text's authenticity and quality:

- literary quality

- historical accuracy

- portrayal of lifestyles

- authentic dialogue

- standards of success

- roles of females, elders, and family

- author's and/or illustrator's background

- illustrations

- relationships between characters of different cultures

- selection of heroes and heroines

- copy right date (outdated books often contain misinformation and/or stereotyping)

It is important that each of these factors are critically examined to determine high quality, authentic texts. For example, Bishop (1990) explained the importance of the use of authentic dialogue instead of Standard English, "Authenticity makes characters believable and identifies them as part of a social group" (para 7). Bishop also suggested that the texts include cultural 'specifics' in order to make the text authentic and universal.

The issue of including high quality, authentic text that positively represents all cultures is not limited to the US. For example, research (McNeil, 2012) that focused on the Métis people, an underrepresented Indigenous people of Saskatchewan, suggested that the inclusion of related, authentic texts is critical because, "books can be used to engender appreciation of the family and 
cultural contexts of emotion socialization in Métis families" (p. 104). Further these and similar related texts must be used "to counter...racially and culturally exclusionary practices in the area of children's texts" (p. 98). When writing about the value of Canadian and Australian Indigenous children's literature, O'Neil (2011) pointed out that, “[B]ecause many Indigenous writers seek to simplify aspects of their stories for young readers, too often the literary and sociocultural value of their works goes unrecognized" (para. 2). However, these texts afford both children and adults the opportunity to learn about other cultures and allow underrepresented groups to 'see' themselves reflected in a positive light.

According to advocates of authentic multicultural literature (Bishop, 1991; D'Angelo \& Dixey, 2001; Jimenez, 2003; Nieto, 2006; Tschida, Ryan, \& Ticknor, 2014) children experience a boost in self-esteem when they feel personally related to the culture reflected in the literature. Conversely, "when children cannot find themselves reflected in the books they read, or when the images are distorted, negative or laughable, they learn a powerful lesson about how they are devalued in the society of which they are a part" (Bishop, 1990, para.4). Therefore, in order to provide a mirror to one's own world and a door into the culture and lives of others (Bishop, 1990) our children must be routinely exposed to high quality, authentic literature. D'Angelo and Dixey (2001) advocated for authentic children's literature in the classroom to scaffold every aspect of literacy including multicultural education. They showed that multicultural literature could be used in the classroom to combat racial prejudice. The children's literature selection was read and discussed by teachers and students to promote positive attitudes, respect, and acceptance of others among students, teachers, and parents. D'Angelo and Dixey suggested that "supplementing traditional curriculum with children's literature representative of authentic life experiences signifies the importance of all races" (p. 85). D'Angelo and Dixey concluded that teachers need to cultivate positive attitudes and behaviors that would allow children to form their own independent beliefs of society.

Although the importance of teaching with high quality, authentic literature has been greatly discussed, Bishop (1997) noted that simple exposure to these texts is not enough. Multicultural texts should be integrated into the curriculum as a natural classroom activity. It is important that teachers understand the multicultural issues, and present their students with strategies to understand the issues. Discussing authentic multicultural topics fosters a positive attitude and social environment in the classroom designating respect between teachers and students. Teachers require extensive preservice experience in order to use multicultural literacy as an effective means to show their students how to listen and discuss multicultural topics with mutual respect or they will miss the opportunity to engage young minds in the discourse of diversity (Nieto \& Bode, 2012; Tschida, Ryan, \& Ticknor, 2014).

\section{Effective teachers of racially, culturally, linguistically and ethnically diverse students}

Nieto's (2006) US-based research explored how to prepare teachers for diverse classrooms, what it means to teach students with diverse backgrounds, and what qualities effective teachers need to possess in order to make positive differences in their students' lives. In addition to their personal qualifications, effective teachers share a passion for their students' diversity, as well as other more personal qualifications, and believe that students have "a right to their identities and their language (p. 469)." Other findings indicated that most preservice teachers have little experience in urban schools with diverse student bodies, and noted that White teachers cannot teach courses in multicultural education ('you can't teach what you don't know') unless they have the "training, experience, and heart to do so" (p. 471). Diversity of experience, 
viewpoints, and expertise needs to be prevalent because it enriches the academic climate for everybody.

According to Nieto (2006) it is critical to place White preservice teachers in urban schools during their field placements and ensure that they are placed with excellent teachers as their mentors in order for them to truly experience diversity and dispel stereotypes. Banks (2007) posited that teachers learn a great deal about their own behaviors when they gain first-hand, a true understanding of another's perspective.

Elementary school teachers need to understand how children learn by example, discussion, and interpretation and to apply this understanding to teaching multicultural literature. In order to accomplish this, teacher educators should provide their students the tools needed "particularly as it relates to the images and messages that these future teachers will send their diverse elementary school pupils about themselves and the world around them" (Tschida, Ryan, \& Ticknor, 2014, p.28). Further, these US teacher educators explained, "We are committed to providing our preservice teachers with conceptual tools that will guide them to make diverse and equitable choices in the literature they have on the bookshelves in their classrooms" (p. 36). Effective teachers, like Mrs. Chatham, expose students and preservice teachers to authentic ways to learn about and connect with other ethnicities through modeling and demonstration.

Social learning theory (Gee, 2001, 2009; Lave \& Wegner, 1991) suggests that children construct meaning based on their social experiences and language discourses within communities of practice (Wenger, 1998). "[T]he experiences people have and how they edit (or interpret) them are founded in a social, interactive, public exterior world" (Gee, 2009, p. 203). Therefore, a program designed to teach diversity in elementary schools should acknowledge diversity and instil in children the importance of valuing other perspectives to broaden their worldviews. Solutions are found in getting everyone involved in open, honest discussions, in which everyone involved feels comfortable and at ease.

Jimenez (2003) suggested that teacher-student relationships are crucial to a student's academic achievement, concluding that multicultural literacy could potentially lead to societal transformations; empowering students by having them recognize themselves as learners. The needs for each student must be considered and regarded as the principle criterion for selection of authentic, multicultural literature. Research shows the positive effects of using multicultural literature in all classrooms, with all students, and that the choice of authentic multicultural literature has an effect on all students (Gray, 2009; Ketter \& Lewis, 2001; Tschida, Ryan, \& Ticknor, 2014).

A study (Taylor \& Hoechsmann, 2011) conducted in Canada that surveyed 942 secondary students, 10 school boards, and 5 provinces regarding multicultural literacy found that although school curriculum was critical to building knowledge to battle cultural racism, outside social factors were equally influential. However, the authors posited that schools have an important role in the development of cultural knowledge in students and, "Like good horticulturalists...they [schools] can seed their gardens and fertilize their soil" (p. 232).

\section{Method}

A qualitative web survey design used in the current study was modified from a pilot study survey first distributed to elementary teachers in a local school district. The first survey was designed as a test for feasibility, ease of use, and flaws in the design. Based on the results, the survey (Appendix A) used in this study was shortened by combining questions and removing redundant questions. In addition, the book list for teachers' selection and usage of multicultural 
books was expanded. High quality, authentic multicultural books were selected from recommendations by the American Library Association (n.d.).

\section{Procedures and Data Collection}

In order to reach as many elementary school teachers from around the US as possible, the revised two-page web survey was sent via Zoomerang.com (an online survey program) to 73 elementary teachers who were identified by peers and colleagues as elementary teachers that may participate in the research. There was a 36\% (26 of 73) return rate. The survey consisted of a set of fifteen (15) questions. Variables pertaining to participant background, their perceptions and use of multicultural literature, and the elementary school district mandates were addressed. Mandates are defined as district, state or federal laws and regulations that schools are required to enact. Often these laws are passed without funding, placing the financial burden on individual districts and states.

Question types included multiple choice (with a text box option), single response (yes/no type), open-ended response, Likert/Likert-like scales, and ranking questions. Four questions reflected the teacher's (participant) background (gender, ethnicity, years of teaching, and education level achieved). Three questions reflected the district and school (administrative support, multicultural education mandates, and resources). Five reflected the teacher's perspectives and practices (teacher definition of multicultural, how multicultural literature was selected, when multicultural literature was used, topic sensitivity, access to multicultural literature). One question asked about student ethnicity and one asked about the school locale (urban, suburban, or rural).

The final question included a list of 41 elementary school multicultural book titles which reflected 11 issues of multicultural topic sensitivity (age, culture, ethnicity, gender, language, morals, race, religion, sexual orientation, socio-economics, and values), and participants were asked to identify how these books were used in the classroom.

Participants (26) were from the US and predominantly from Northeastern states (19). Others were from Western states (2), the Midwest (3), and the Southeast (2). 25 were females, with one male. Respondents self-identified as Caucasian (22), African American (1), and Hispanic (3). Average length teaching experience was 8 years, and 21 participants taught in suburban schools, 4 in urban schools and 1 in a rural school. Sixteen participants held a graduate degree, 9 held Bachelor's degrees, and 1 held a PhD.

\section{Data Analysis}

Data were analyzed using constant comparison methods (Creswell, 2011) to discover patterns in the participants' responses and to compare them with emerging themes. When appropriate, (i.e., demographics and background, school district mandates, books read in class) question responses were entered into an excel spreadsheet and data were aggregated. The Likert style responses were tallied and percentages for each question were generated. The first author provided initial themes (i.e., mandated versus non-mandated school practices, and the role of the school principal), then the second author coded the data and verified the themes. Discussions ensued where there were discrepancies and disagreements. When consensus was reached, the selected themes were coded according to frequency (Denzin \& Lincoln, 2011) as they appeared in both the Likert and open-ended survey responses. Reliability was afforded through systematic analyses of the data which yielded several common themes within and across participant 
responses (Mertler \& Charles, 2011). To confirm our findings we used direct quotes from the participants.

\section{Findings}

Analysis of the data revealed the following trends related to this study of elementary school teacher perspectives on the use of multicultural literature in their classrooms: (1) Strong support for multicultural education by elementary school administrators encourages reading of multicultural literature in schools; (2) Mandating multicultural education does not always increase the reading of multicultural literature in elementary schools, and; (3) Administrators involved with mandates may limit the use of multicultural literature by promoting close adherence to curriculum for multicultural literature selections.

\section{Strong Administrative Support Promotes the Use of Multicultural Literature in Schools}

While analysis revealed that all (26) the elementary school teachers surveyed used multicultural literature some of the time (e.g. for holidays, celebratory months, and/or cultural events) during the school year, the data also indicated that with strong support of principals, the use of multicultural literature increased.

Mandated schools (11 of 26 identified in this study) are required to teach multicultural education. One respondent in a mandated school said that "much of the literature is provided for read alouds, shared reading and guided reading during language arts, science, and social studies" but added that she "also selects her own [books] from the public library". This study also indicated that non-mandated teachers having strong administrative support used multicultural literature regardless of mandates, which suggested strong and supportive leadership can make a significant difference (27\% agree; $73 \%$ strongly agreed that their principals supported the use of multicultural literature).

\section{Mandating Multicultural Education Alone Does Not Increase the Reading of Multicultural Literature in Elementary Schools}

One might think that teachers in mandated schools would have reported that they use multicultural literature all the time, but findings indicated this is not so. Of the 11 teachers in mandated schools, none $(0 \%)$ reported using multicultural literature all the time, $67 \%$ reported sometimes as opposed to the non-mandated teachers who said they used it always (53\%) and sometimes $(33 \%)$. For example, one respondent from a non-mandated district expressed how and when she used multicultural literature:

Most of the stories during the Reading block are a mixture of multicultural literature. During Social Studies is where I use most of my own selection of multicultural books. Native American and African legends, poems from all cultures, and songs and dances from around the world are some of my favorite ways to use multicultural literature.

Whereas a respondent in a mandated school stated:

Our curriculum is embedded with multicultural literature. There are many different cultures in our stories that we read in our anthology...I select literature based on holidays or special days that (we) have in our community. 
Although the respondent from the mandated school used an anthology that included multicultural literature, she appeared to have narrowly interpreted the meaning of a multicultural curriculum by limiting her supplemental text selections to holidays or special days. In contrast, the teacher in the non-mandated school selected and integrated multicultural literature across the curriculum in Social Studies and reading lessons in what Bishop (1997) called "a natural classroom activity."

Some of the teachers reported that they were uneasy using books on diverse subjects that they were unfamiliar with or unknown to them (e.g. sexual orientation, diverse cultures).

When asked, "Are there any topics you consider too sensitive to use in class" (question 13), nine simply replied, 'no', but other responses varied:

Not really, I just won't go into it graphically

No, but I do limit to a degree - first grade

Probably

Other respondents were more specific:

Sexuality. I'm not sure my district would agree

Same sex relationships

Sexuality and all that is related

Rape and abortion

Marriage and mating practices of some cultures

Last year, I had a child with 2 Moms. We let it be.

Need to be developmentally appropriate/purposeful

Depends on group

Topics are open; elements of topics need be appropriate

Yes, extremely violent acts from prejudiced people upset the children

Sexual orientations

Nieto and Bode (2012) addressed this sensitivity issue by strongly urging preservice teachers to tackle the "uncomfortable" topics and issues. This discomfort was also apparent in participants' selection of award winning texts that were more familiar and comfortable: A Chair for My Mother (Williams, 1982) was cited as used by 20 of the respondents to discuss socioeconomic differences, and The Polar Express (Van Allsburg, 1985) was used by 16 to discuss values. Both of these selections were used most often as read alouds. The popularity of these selections may also suggests that these titles are 'favorites' of the teachers, and students may assume that the perspective of the text is important or correct because it is their teachers' preference.

Nieto (2006) argues that teachers cannot remain "neutral" to the differences and instill a sense of self-esteem in their diverse students unless they earnestly know and take a vested interest in the cultural lives of their students. Teachers should be introduced to a variety of different multicultural populations during preservice, before taking on any teaching position, and continue to push those discussions surrounding multicultural topics without fear, remorse, hesitation, or anxiety. If teachers are too fearful to discuss such important multicultural topics such as sexual orientation during read alouds, when a "teaching moment" arises, then they are teaching our children, our students, our future leaders of society to be fearful of uncomfortable topics. While statistics show that White females dominate the teacher workforce in all settings and locales (urban, suburban, and rural), proper training, authentic multicultural classroom 
literature, strong multicultural preservice experience, appropriate teacher selection and use of multicultural literature and strong administrative support may bring about a change and bridge the diversity gap.

A strongly motivated principal can connect to peers, parents, school board, and politicians to promote multicultural education. The strong support of elementary school administrators for multicultural education encourages reading of multicultural literature in schools. Strong principal support should be encouraged. When multicultural literature is read aloud and discussed throughout the school year, not just during culture specific events, it engages students to challenge and examine assumptions, inconsistencies, and/or illogical conclusions thereby reducing racism, stereotypes, and bias (Dressel, 2005; Özturgut, 2011).

It appears that elementary school teachers use multicultural literature more frequently when they have strong administrative support, regardless of their students' or their own ethnicity. The results here correlate with Gray's (2009) study which indicated that the ethnicity of the teacher was not a factor regarding selection of multicultural literature. The increase in the frequency of use may be due to the support teachers have when using multicultural literature in mandated schools. This finding is notable in comparison to Ketter and Lewis' (2001) study where the teachers did not have support from administrators. This situation resulted in teacher resentment, parental disputes, and student abasement. Teachers also needed to be taught to read literature in "culturally critical" ways, so a multicultural perspective could be selected and used throughout the school year.

Ketter and Lewis (2001) concluded that strong principal support alleviates the fear teachers have when confronted with potentially sensitive multicultural literature issues which need to be discussed with students to promote inclusion and self-esteem. Social learning and cognitive models need to be understood by teachers implementing curriculum designed to decrease racist beliefs and negative attitudes in young children (Cristol \& Gimbert, 2008).

\section{Mandates May Limit the Use of Multicultural Literature by Promoting Close Adherence to Curriculum for Multicultural Literature Selections}

Eleven of 26 respondents reported they were mandated to use multicultural literature while 15 said they were not. Interestingly, this study revealed that the majority of teacher participants defined multicultural literature in narrow terms, regardless of mandates. For example, when asked to define multicultural literature (question 7), 11 reported that they used the term culture, 2 used nationality, and 1 used diversity, and 1 used race as part of their definition. Participants reported that values was the topic most often used and discussed, while sexual orientation was the least.

Administrative support appeared to increase the use of multicultural literature, and possibly with fewer limitations on the selection process because these teachers selected their own materials. Teachers in mandated elementary schools may rely exclusively on curricula for selection of multicultural literature. Teachers in non-mandated schools chose multicultural literature to meet the needs of their students. For example, one respondent used multicultural books to introduce a new and diverse student. When asked to explain how and when multicultural books were used, (question 11), one elementary teacher responded:

Whenever I can. During read alouds, I try to find books with multi-racial or cultural characters. We also discuss and read about holidays around the world. We have an Indian girl so we all celebrated Diwali. We will also be celebrating the Chinese New Year soon. 
Another participant indicated that she makes sure she has plenty of

white, black, and Hispanic books. Also, when I have Asian or other races in our class, I search out books that show their cultures also. Last year we had a boy from Vietnam so we learned to count to 20 in Vietnamese, as well as English \& Spanish.

As Dressel's (2005) study pointed out, White teachers rarely see themselves as having a race, accept themselves as being the cultural norm, and anyone different or non-white is viewed as an outsider. Therefore, it stands to reason that the definition of multicultural employed by these teachers is limited and narrow, avoiding issues like sexual orientation, and other "sensitive" subjects. Teachers teach what they know. According to Ketter and Lewis (2001) teachers are afraid to teach about race, fearing they might say something wrong, offend, promote dissention and insubordination, or be seen as inappropriate. They preferred to remain "neutral" as confirmed in this study. Such perspectives pertain to other "sensitive" multicultural topics, as well, in which White teachers prefer teaching commonalities across cultures such as, "good values that stable families hold" or the "White Middle Class norm" (Ketter \& Lewis, 2001; Lee \& Dallman, 2008).

Our findings suggest that regardless of how multicultural is defined, narrow or broad; it is possible to solicit positive results and attitudes from students toward others by reading and discussing multicultural literature. Further, this study supports the findings of others (Cristol \& Gimbert, 2008; D’Angelo \& Dixey, 2001; Kim, Grief-Green, \& Klien, 2006) that children can learn more about themselves and others if:

(1) Preservice teachers experience diversity firsthand, by working in schools and communities that acknowledge and embrace the broad definition of diversity, (Lee \& Dallman, 2008; Nieto, 2006);

(2) Teachers get supported by discussing these topics with their principals and aim toward involving parents in deciding how to address them, and what depth to address them (Ketter \& Lewis, 2001, Lee \& Dallman, 2008);

(3) Adequate follow up is provided from research, principals, librarians, and the community;

(4) Teachers understand the components of multicultural literature in the broader term and take any and all opportunities to explain and discuss an otherwise difficult topic;

(5) Students are permitted to look into any part of any given topic with parental approval, (Ketter \& Lewis, 2001, Lee \& Dallman, 2008); and

(6) Teachers increase the discussion, use a variety of high quality, authentic multicultural literature in their classrooms (Jetton, \& Savage-Davis, 2005, Dressel, 2005; Gee, 2012; Gray, 2009; Taylor \& Hoechsmann, 2011; Tschida, Ryan, \& Ticknor, 2014).

\section{Implications}

The research questions investigated in this study have led to new and important findings which can have a profound impact on current educational practices, thinking, and financing of multicultural education curriculums. The most significant research finding is the extremely effective power of strong administrative support for multicultural literature, indicating the need to educate elementary school administrators to be strong supporters of multicultural literature. As well, educating the teachers in their schools to appreciate and teach multicultural literacy would be an efficient and cost effective means for promoting multicultural education. A great 
deal of money, time, and effort would be saved if school boards and legislators were removed from the decision process while entrusting local administrators to make decisions appropriate for their community. In addition, using elementary school administrators to promote multicultural literacy, rather than imposing district mandates, would seem to obviate most of the sociopolitical obstacles incurred in developing and implementing district mandates. This would also empower local school administrators by involving them in decisions that reflect their communities instead of mandating requirements that appear to be satisfied in a perfunctory fashion. Further, in the process, elementary school administrators might build trust, understanding, and respect between themselves and teachers. Finally, teachers who have strong support from their administrators to implement an effective multicultural literacy program might be encouraged to take the kinds of risks that make multicultural education inclusive, relevant, and exciting for all students.

\section{Conclusion}

It takes time, money and political will to create a mandate, while a strongly motivated principal can move much more quickly to make changes in an elementary school. In the US, funding decisions are often made at the local district level, so 'buy-in' by school leaders is required because, "as the instructional leader in a school setting, a principal's major task is to interpret state and district policies for the purpose of leading student instruction and achievement" (Massey, 2012, p. 66). As with any curriculum decision, funding also plays an important role therefore obtaining administrator support is critical. A strongly motivated principal can connect to peers, parents, school board, and politicians to promote multicultural education. The strong support of elementary school administrators for multicultural education can encourage reading of multicultural literature in schools.

Mandating multicultural education increases reading of multicultural literature in schools, however, it may limit the selection process for teachers. Findings suggest that non-mandated elementary school teachers use their classroom libraries as a source of multicultural literature more than teachers in mandated elementary schools, who may rely exclusively on curricula for selection of multicultural literature. Administrators involved with mandates may limit the use of multicultural literature by promoting close adherence to curricula for multicultural literature selections.

Although this study examines US schools, the theoretical underpinnings that support this study may be applied more globally. That is, all students must see themselves in the books they read, and to that end each school should consider their population and seek out high quality, authentic texts to fill their classroom libraries. In addition, these libraries should contain a vast amount of diverse literature to broaden children's understanding and perspectives about diverse cultures other than their own. As Bishop (1990) suggested, texts should provide windows to view the world, sliding doors to pass through, and mirrors that reflect our lives and experiences. Further, multicultural texts should be naturally integrated into the curriculum where students are exposed to diversity as a regular part of their education and not just 'hauled out' for special holidays.

This study is limited by the relatively small sampling of elementary teachers who were predominantly White and from Northwestern US states. In addition, participants were volunteers which may affect their responses. These factors limit transferability to other populations and we suggest that a larger study drawing from a wider, and more varied demographic and socioeconomic population, is warranted. 
Engaging discourse comes from personal stories such as the discovery of Karen Pierce and her grandfather's contributions toward making the US more accepting of multicultural diversity. Stories such as these make it possible for us to gain firsthand knowledge about the rich contributions made by various individuals from all backgrounds.

\section{Future Research}

This study emphasizes the importance of the school principal's role in the selection and use of multicultural literature in the curriculum. Research in the field of Educational Leadership supports this finding in that the "key to effective leadership is the collaboration of the principal as instructional leader and other school personnel as together they analyze and discuss school needs" (Massey, 2012, p. 66).Therefore, future research exploring the role of principals and school administrators would be beneficial to understand and improve the use of multicultural literature to diminish prejudice and broaden our students' worldviews. In addition, studying a larger and more diverse group of teachers would add greater insight into the ways in which elementary teachers use multicultural literature in their classrooms. Finally, the study of teachers' use of multicultural literature in various countries would extend the knowledge base and increase cultural competency.

\section{References}

American Library Association (n.d.). Retrieved from http://www.ala.org/emiert/usefullinks/links Banks, J. A. (2007). Educating citizens in a multicultural society (2nd ed.). New York, NY: Teachers College Press.

Bishop, R.S. (1990). Mirrors, windows, and sliding glass doors. Perspectives: Choosing and Using Books for the Classroom, 6(3), ix-xi.

Bishop, R. S. (1991). Evaluating books by and about African-Americans. In M.V. Lindgren, (Ed.), The multicolored mirror. Fort Atkinson, WI: Highsmith Press.

Bishop, R. S. (1997). Selecting literature for a multicultural curriculum. In V.J. Harris (Ed.), Using multiethnic literature in the $K-8$ classrooms (pp. 1-19). Norwood, MA:

Christopher-Gordon.

Cristol, D., \& Gimbert, B. (2008). Racial perceptions of young children: A review of literature post-1999. Early Childhood Education Journal, 36(2), 201-207. doi:10.1007/s10643008-0251-6.

Coulby, D. (2011). Intercultural education. The theory deficit and the world crisis. In C.A. Grant \& A. Portera (Eds.), Intercultural and multicultural education (pp. 98-109). London, UK: Routledge.

Cooperative children's book center. n.d.: Retrieved from http://ccbc.education. wisc.edu/books/detailListBooks.asp?idBookLists=42

Creswell, J. W. (2011). Educational research: Planning, conducting, and evaluating quantitative and qualitative research (4th ed.). New York, NY: Pearson.

D’Angelo, A M., \& Dixey, B. P. (2001). Using multicultural resources for teachers to combat racial prejudice in the classroom. Early Childhood Education Journal (29), 2, 83-87.

Denzin, N. K, \& Lincoln, Y. S. (Eds.). (2011). Handbook of qualitative research, (4 ${ }^{\text {th }}$ ed.). Thousand Oaks, CA: Sage.

Dressel, J. H. (2005). Personal response and social responsibility: Response of middle school students to multicultural literature. The Reading Teacher, 58 (8), 750-764. 
Gee, J. P. (2001). Reading as situated language: A sociocognitive perspective. Journal of Adolescent and Adult Literacy, 44(8), 714.

Gee, J.P. (2009). Reflections on reading Cope and Kalantzis' Multiliteracies: New literacies, new learning. Pedagogies: An International Journal, 4, 196-204. doi: 10.1080/15544800903076077

Gee, J. P. (2012). Social linguistics and literacies: Ideology in discourses (4th ed.). New York, NY: Routledge.

Gray, E. S. (2009). The importance of visibility: Students' and teachers' criteria for selecting African American literature. The Reading Teacher, 62(6), 472-481.

Harada, V. H. (1995). Issues of ethnicity, authenticity, and quality in Asian-American picture books, 1983-93. Journal of Youth Services in Libraries, 8, 135-149.

Higgins, J.J. (2003). Multicultural children's literature: Creating and applying an evaluation tool in response to the needs of urban educators. Retrieved from http://www.education.jhu.edu/PD/newhorizons/strategies/topics/multiculturaleducation/multicultural-childrens-literature

Jetton, T. L., \& Savage-Davis, E. M. (2005). Preservice teachers develop an understanding of diversity issues through multicultural literature. Perspectives, 7(1), 30-38.

Jimenez, R. T. (2003). Literacy and Latino students in the United States: Some considerations, questions, and new directions. Reading Research Quarterly, 38(1), 127-8.

Ketter, J., \& Lewis, C. (2001). Already reading texts and context: Multicultural literature in a predominantly white rural community. Theory Into Practice, 40(3), 175-183.

Kim, B., Grief-Green, J., Klein, E. (2006). Using storybooks to promote multicultural sensitivity in elementary school children. Journal of Multicultural Counseling and Development, (34) 223. Retrieved from http://connection.ebscohost.com/c/articles/23054879/usingstorybooks-promotemulticultural-sensitivity-elementary-school-children

Ladson-Billings, G. (2003). Critical race theory perspectives on the social studies: the profession, policies, and curriculum. Greenwich, CT: Information Age Pub.

Lave, J., \& Wenger, E. (1991): Situated learning: Legitimate peripheral participation. Cambridge: Cambridge University Press.

Lee, S. \& Dallman, M. (2008). Engaging in a reflective examination about diversity: Interviews with three preservice teachers. Multicultural Education, (15)4, 36-44.

Retrieved from: http://eric.ed.gov/?id=EJ809074

Lu, M.Y. (1998). Multicultural children's literature in the elementary classroom. Bloomington, IN: ERIC Clearinghouse on Reading English and Communication. (ERIC Document Reproduction Service No. ED423552).

Lund, D.E. (2006). Waking up the neighbors: Surveying multicultural and antiracist education in Canada, the United Kingdom, and the United States. Multicultural Perspectives, 8(1), 3543.

Massey, S. L. (2012). Leadership in reading. Illinois Reading Council Journal. (40)3, 65-69.

McNeil, B. (2012). A case for using Indigenous children's literature for emotion socialization in schools. Global Studies of Childhood, 2(2), 97-105. doi.org/10.2304/gsch.2012.2.2.97

Mertler, C. A. \& Charles, C. M. (2011). Introduction to educational research (7th ed.). New York, NY: Pearson.

National Association for Multicultural Education (2003). Resolutions and position papers. Retrieved from: http://www.nameorg.org/2003_name_position_statements.php 
National Association for Multicultural Education (2016). Definitions of multicultural education. Retrieved from http://www.nameorg.org/definitions_of_multicultural_e.php

Nieto, S. (2006). Solidarity, courage and heart: What teacher educators can learn from a new generation of teachers. Intercultural Education, 17(5), 457 - 473.

Nieto, S., \& Bode, P. (2012). Affirming diversity: The sociopolitical context of multicultural education $\left(6^{\text {th }}\right.$ ed.). Boston, MA: Pearson.

O'Neil, A. (2011). Aboriginal Australian and Canadian First Nations children's literature. CLCWeb: Comparative Literature \& Culture, 13(2), 1.

Özturgut, O. (2011). Understanding multicultural education. Current Issues in Education, 14(2). Retrieved from http://cie.asu.edu/ojs/index.php/cieatasu/article/view/732

Palaiologou, N., \& Faas, D. ( 2012). How 'intercultural' is education in Greece? Insights from policymakers and educators. Compare: A Journal of Comparative and International Education, 42(4), 563-584.

Taylor, L., \& Hoechsmann, M. (2011). Beyond intellectual insularity: Multicultural literacy as a measure of respect. Canadian Journal of Education, 34(2), 219-238.

Tschida, C., Ryan, C. L., \& Ticknor, A. S. (2014). Building on mirrors and windows: Encouraging the disruption of "single stories" through children's literature. Journal of Children's Literature, 40(1), 28-39.

Wenger, E. (1998). Communities of Practice: learning, meaning and identity. Cambridge: Cambridge University Press.

\section{Children's Literature Cited}

Van Allsburg, C. (1985). The polar express. New York: Houghton-Mifflin. Williams, V. B. (1982). A chair for my mother. New York: Greenwillow Books

\section{Appendix A-Web Survey}

Teacher's Perspectives on the Use of Multicultural Literature in Their Classrooms

The purpose of this study is to investigate how Elementary school teachers across the country use multicultural literature in
classrooms. All identities will be kept confidential and pseudonyms will be used. Thank you for your time answering this
Initials:
For the following: First use your cursor to Highlight, then box, "X“, underline, and/or briefly fill in using italics, color and/o
change of font.
1. What's your gender?
2. What's your ethnicity?
Caucasian:
Asian:
Other (please clarify):
3. Your education level?
Bachelor's
4. My school is in an ... Murban


5. Years of teaching experience:

6. Please circle the ethnicity and indicate about how many of your students who are:

\section{Caucasian:}

Asian:

Other (please clarify):

African American:

Native American:
Pacific Islander:

\section{Hispanic:}

7. How do you define multicultural literature?

8. I believe my principal supports teachers using multicultural literature.

Strongly disagree Disagree $\quad$ Agree Strongly agree

9. I use multicultural literature in my classroom:

Never Not very often Sometimes Most of the time

Always

10. Does your district include a multicultural curriculum requirement?

11. Please explain how and when you use multicultural books.

12. How do you locate and select literature?

13. Are there any topics you consider too sensitive to use in class?

14. How many multicultural books do you have in your classroom? (Circle the best answer)

Less than $10 \quad$ 11-15

$16-2021-25$

$26-30$

$30-35$

If more than 35 , how many?

15. Below is a list of multicultural literature for elementary school students. Please checkmark those titles you may have used in your classroom as a Read Aloud, Library Selection, Favorites (*S for student, $\mathrm{T}$ for teacher, $\mathrm{X}$ for both), and Other (say how used).

\section{Multicultural Literature for Elementary Schools}

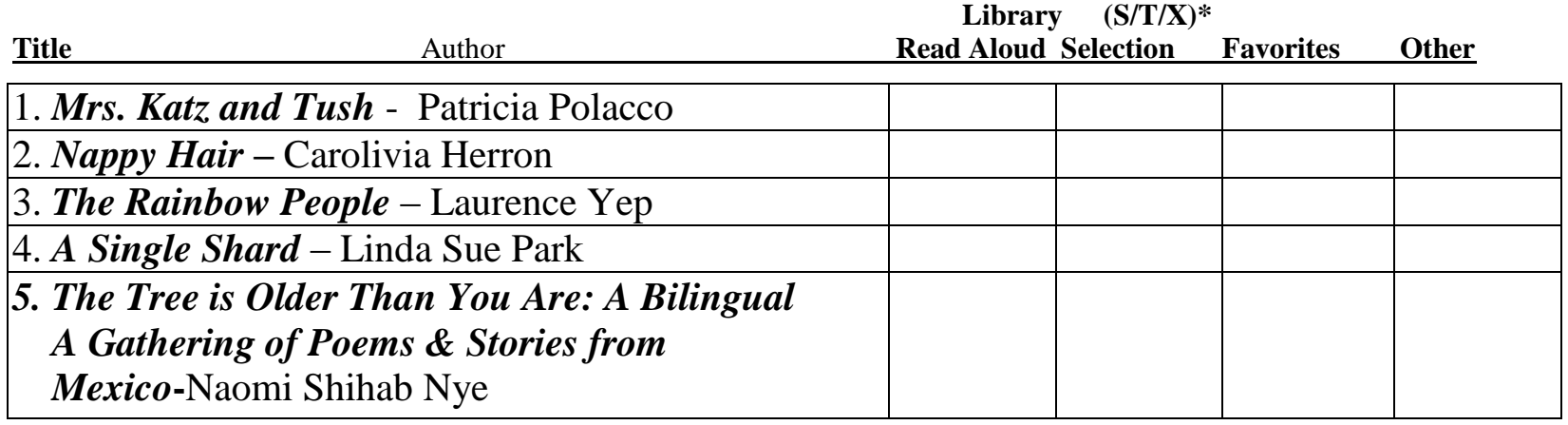


6. Fox Song - Joseph Bruchac

7. Remember That- Leaslea Newman

8. Martin Luther King Jr. Day - Margaret McNamara

9. Too Many Tamales - by Gary Soto

10.Tar Beach - Faith Ringgold

11. Baseball Saved Us - Ken Mochizuki

12. Hair/Pelitos - Sandra Cisneros

13. Mirandy and Brother Wind - Patricia C. McKissack

14. Father's Rubber Shoes - Yumi Heo

15. Roll of Thunder, Hear My Cry - Mildred D.

Taylor

16. Molly's Pilgrim - Barbara Cohen

17. The Giver - Lois Lowry

18. A Sporting Chance - Andy Steiner

19. Meet Danitra Brown - Nikki Grimes

20. The Case of the Good-For-Nothing

Girlfriend: $A$

Nancy Clue and Cherry Aimless Mystery

- Mabel Maney

21. Dare, Truth or Promise (Livewire) - Paula Boock

22. The House You Pass on the Way - J.

Woodson

23. We Share Everything! - Robert Munsch

24. This Little Piggy's Book of Manners - K M.

Allen

25. The Polar Express - Chris Van Allsburg

26. The View From Sunday - E. L.

Konigsburg

27. Sylvester and the Magic Pebble - by Wm. Steig

28. Wemberly Worried - Kevin Henkes

29. Chester's Way -Kevin Henkes

30. Bootsie Barker Bites - Barbara Bottner

31. Anastasia, Absolutely - Lois Lowry

32. The Story of Divaali - Verma Jatinder

33. Night - Elie Wiesel

34. And Tango Makes Three - Justin

Richardson

35. When Heroes Die - Peggy Raife Durant

36. Mama Eat Ant, Yuck! - Barbara Lynn

Edmonds

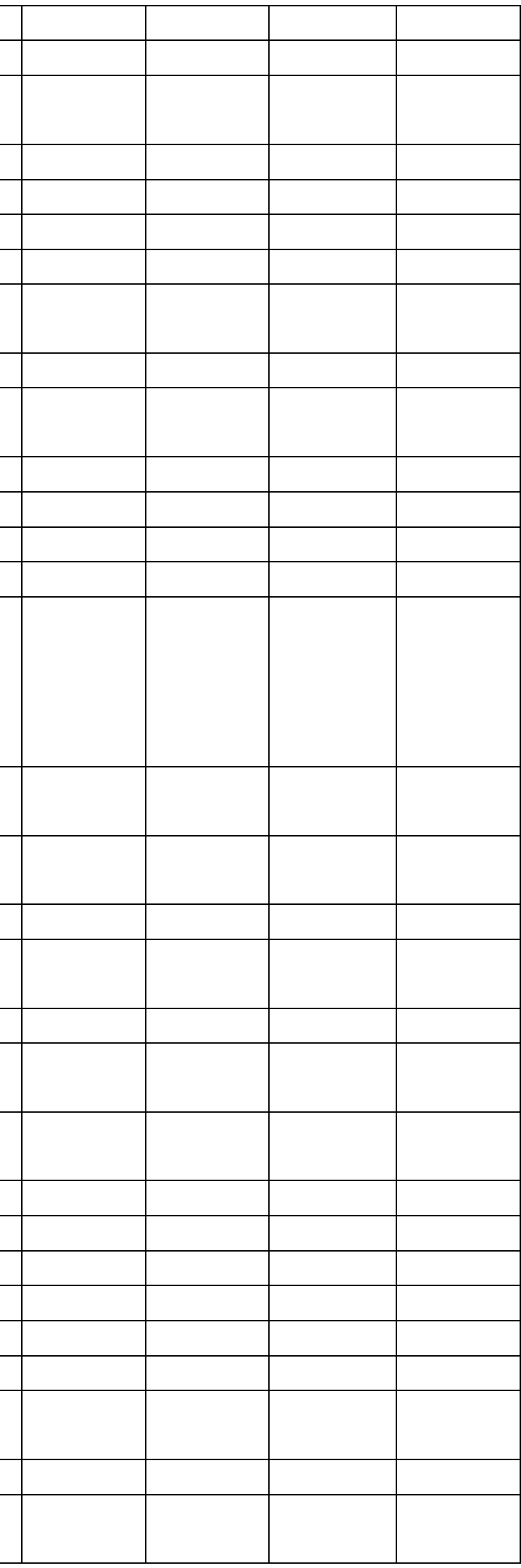




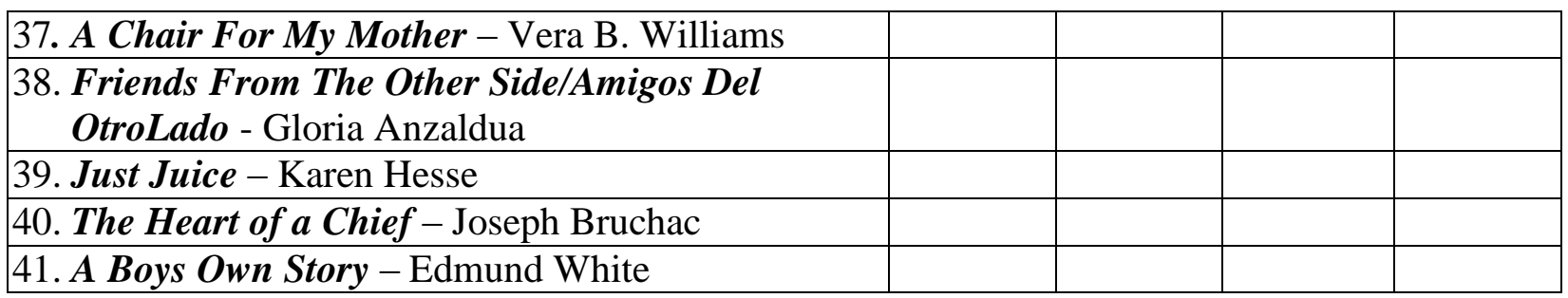

Author Biographies

Karen Holland is a graduate of the Master's in Literacy program at William Paterson University. Her interests include multicultural literature and elementary education. She is currently teaching reading in a Florida school district.

Geraldine Mongillo, $\mathrm{PhD}$, is a Professor of Literacy and the chair of the Department of Educational Leadership and Professional Studies at William Paterson University of New Jersey. Dr. Mongillo's interests include adolescent literacy, multicultural literature, and the preparation of reading specialists. Recent publications appeared in the American Teacher Education Yearbook XXI, Teacher Education and Practice, and the Journal of College Reading and Learning. She can be reached at mongillog@ wpunj.edu 